\title{
Process and the method of application of information systems engineering supervision
}

\author{
Xu Yan-wen \\ Information technology college, Henan University of TCM, Zhengzhou, China \\ e-mail: xyw@hactcm.edu.cn
}

Keywords: information system supervision; life cycle; Assessment Model

\begin{abstract}
In this paper, information system information system supervision in all stages of the life cycle of the role of software project supervision assessment model is described, analyzed and demonstrated between owners and information system contractors to increase the need for supervision, through the information system Management of effective assessment, and enhance the organization of software construction and normative.
\end{abstract}

\section{Introduction}

Software Project Management is the appropriate qualifications established by law and the engineering supervision unit, commissioned by the owners of units, according to state laws and regulations, technical standards and information systems engineering supervision contract, the implementation of information systems engineering project supervision and management [1]. China's Software Project Management in a fledgling stage, the relevant standards and specifications is still in short. Information system supervision relationship, the owners (construction unit) to grant supervisory side project management and control of power, supervision units in the project management activities on behalf of the owners [2]. Some Project Management Company based on information about technical specifications and information system project contract, his or her own experience, supervision, supervision of the company's practice of most fragmented, making it very hard to measure the supervision of a data evaluation system. Based on meticulous research of the characteristics of information system based on the argument between the owners and information system contractors to increase the need for supervision, and supervision in the information system development in the future to make possible a preliminary discussion.

\section{INFORMATION SYSTEM INFORMATION SYSTEM SUPERVISION IN ALL STAGES OF THE LIFE CYCLE}

\section{A. Information system Lifecycle}

Full life cycle information system in accordance with ISO's definition of full life cycle information system phase into the implementation phase, use phase and maintenance phase, which is further subdivided into the implementation phase of preparation, design and construction. The actual situation in our country, the information system life cycle has four phases. The first stage is "born" in phase, the system of decision-making stage ", once the system through the decision-making, the system enters the second stage, design stage, stage set up in the system model. The third stage is" production " phase, the system was put into the development and construction. The fourth stage is the "operation and maintenance" phase, that phase of the system into operation.

B. Information system Supervision in information system role in the life of the whole

Software Project Management is a information system a social governance structure, is an independent third party to provide information system, planning and organization, coordination and communication, control and management, monitoring and evaluation services, the purpose is to support and ensure The success of information system. Information system, information system, supervision should be in all the stages of the design stage of supervision accordingly to reflect the 
process of information system in the actual situation.

1) The design phase of information system supervision

Closely with the supervising engineer and the owner of the design, the qualification and qualification designers, design and audit, design schedule inspection, design review results and related documents, design collaboration with external and internal tracking of inspection.

2) Supervision of the implementation phase of information system

Supervision Management Engineer on the construction phase and construction should be practice tracking the progress of synchronization. The system tracks the major issues: a review of approved construction contractors proposed schedule and check the implement of

information system, collection, sorting engineering documents, written project summary, the construction unit in the future on the new system's operation and maintenance are to lay the foundation, etc. .

3) Information system Operation \& Maintenance Supervision

In the Operation and Maintenance Management Engineer reviewed the operating system, applications and other software configuration and design of the compliance program to detect functional performance verification system of compliance with the contract, check the implementation of training programs to help users develop the system operation and management rules and regulations and so on.

\section{INFORMATION SYSTEM SUPERVISION EVALUATION MODEL}

Information Engineering Supervision goal is to achieve the interests of [3-4]. Software Project Management in the assessment process, the owners and information system contractor, after contract to form a binary relation. Both the owner or the development side, unilaterally solve the two problems are difficult, but the role of supervision can mitigate the asymmetric pressure on the parties. Therefore, the emergence of third-party supervision are inevitable. Supervisor and the owners and developers have become ternary square organizational relationship.

Software Project Management to increase the project cost though, but in the long run, there is increased supervision of the ratio of success of the project, reducing the loss of the net assets of the community. Supervision of the standard management approach, tools and processes to ensure the project quality, reduce maintenance costs of the project, thus reducing the project's operating costs. At the same time when the software project supervision, ongoing assessment of the way through the data analysis, quantitative measure of the final result. Assessment of information system supervision, its objectives are: within a certain time, within a certain cost, software completion of the project was the supervision function points, reached the quality requirements. The model shown in Figure 1.

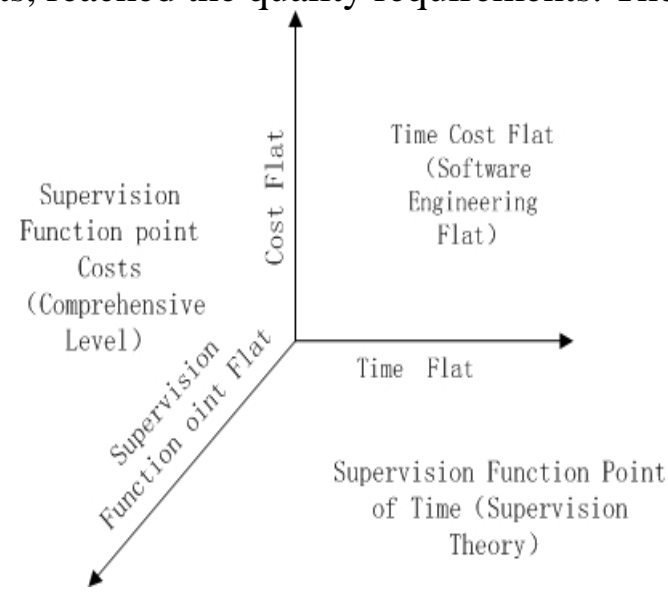

Fig.1. Software Project Management Assessment dimensional model

Finally, complete content and organizational editing before formatting. Please take note of the following items when proofreading spelling and grammar: Software Project Management is the outsourcing project, its assessment of the model was statistically significant following formula: 


$$
S S E=\left[\left(\frac{C_{1}}{C D_{1}} * \frac{S F P_{1}}{S F P D_{1}}\right)+\left(\frac{C_{2}}{C D_{2}} * \frac{S F P_{2}}{S F P D_{2}}\right)+\ldots+\left(\frac{C_{i}}{C D_{i}} * \frac{S F P_{i}}{S F P D_{i}}\right)\right] / T_{i}
$$

Among them, the representative of the quality assessment of information system supervision, representing the first milestone, the cost of how much to spend on behalf of the first milestones, budget spending value; representative of the second milestone, the cost of how much to spend on behalf of the first Two milestones, budget spending value; the project milestone has been accumulated to the amount of the first case when i milestones that the current calculation of the milestone.

The three aims of information system supervision throughout the entire process, we give the first formula, not weight, in information system projects, the present trend is that more and more the need for engineering projects weighting factor, which is in a different milestone, its degree of importance of the object of concern is different, information system project.

$$
\begin{aligned}
& S S E=\left[\left(\frac{C_{1}}{C D_{1}} * \frac{S F P_{1}}{S F P D_{1}}\right) * \lambda_{1} * \mu_{1} * \beta_{1}+\left(\frac{C_{2}}{C D_{2}} * \frac{S F P_{2}}{S F P D_{2}}\right) * \lambda_{2} * \mu_{2} * \beta_{2}\right. \\
& \left.+\ldots+\left(\frac{C_{i}}{C D_{i}} * \frac{S F P_{i}}{S F P D_{i}}\right) * \lambda_{i} * \mu_{i} * \beta_{i}\right] / T_{i}
\end{aligned}
$$

Representative costs of weight, time, weight, quality, weight, and his subscript range from 1 to $\mathrm{i}$. Software Project Management Assessment contained within the overall model is a five elements: Management Object, supervision objectives, supervision content, security, supervision and implementation[5-7]. Through comprehensive calculation and analysis, we can arrive at a measurable result, which can make Software Project Management has a fundamental basis.

At present, the risk of large information system projects, construction of market further regulation is needed. To reduce the risk of software construction, standardized information system construction market, to ensure the interests of both owners and construction units, construction of information system structured, standardized assessment of supervision becomes more urgent and important.

\section{THE NEED FOR INFORMATION SYSTEM SUPERVISION AND DEVELOPMENT TRENDS}

Information system has made in the last 10 years rapid development, now in all walks of life have a lot of money for the construction of information, industrial automation control systems, corporate ERP systems, digital campus system software projects continue to emerge, and over the type Development[8-10]. However, information system supervision of the origin, development and related laws and regulations is not quite complete, the software works and supervision is far from mature compared to construction supervision, project supervision of maturity is still relatively poor, so in the future software development project supervision there is still great room for development projects in information system, information system supervision will play an increasingly important role. After the process of building information and information system supervision for many years running and development, information system supervision are shown so on, a few issues to address, the software development project supervision will also be accompanied by resolution of these issues.

Information Project Management market is not a standardized and orderly competition. Information system supervision domestic market is not quite standard, the state supervision and inadequate supervision of the market, resulting in supervision of the market was chaotic competition among enterprises is largely dependent relationship between competition and price competition. A large number of tasks and supervision units competing for the contract lower prices, and even take to the kickbacks, commissions and other unfair means of drawing customers. These departments should have a good means of supervision; otherwise the situation will be difficult to improve. 
Part of the Information Project Management internal management turmoil, only money, less work, poor sense of service. On the whole, the level of standardized management supervision enterprises in Guangxi uneven. Management generally small-scale enterprises, financial strength, technical strength is weak, difficult to domestic and foreign large companies to compete cause. Some supervisors discipline loose, or even use work will take, take, to greatly damaged the reputation of the profession supervision. Although the nominal supervision units have a number of levels of qualification certificate and business license, but not their regular employees, do not possess the qualifications in supervision. Made task on a few people on the provisional Minato, mission was over, staff on the dissolution, not to mention the supervisor to carry out standardization work, so the supervisors their quality is not high.

To sum up, information construction in full swing with the launching of the software project supervision is being gradually accepted and our applications, in information technology will play an increasingly important role, supervision companies should pay attention to their quality assurance and management, in accordance with the specifications required their own [11]. Software Project Management will be a step by step toward standardized assessment, institutionalization, specialization and socialization, and gradually evolved into a mature and perfect markets, the tide in the information technology play a greater role.

\section{Acknowledgement}

In this paper, the research was sponsored by the Nature Science Foundation of Henan Province (Project No. 13A520007) and Youth Fund Project of Henan Institute of Science and Technology (Project No. 2012GGJS-225).

\section{References}

[1] Li Weihong. Modern computer. Information System Engineering and Project management compared to 2009.

[2] Xiang Yong. Chongqing Architecture University. Project Management under Asymmetric Information Management Performance Theory, 2012.

[3] Hong-chang. Beijing University of Technology. Based on the interests of achieving and risk-driven Information Engineering Management, 2011.

[4] either the Peng. Shandong University. To organize and coordinate the information system supervision for the center mode of analysis and research 2008.

[5] He Feng. Science and Technology Information. On the Improvement of Information system Project Management, 2009.

[6] Liu Yang. Tianjin University School of Management. Software Project Management Control and Evaluation of the objectives of 2006.

[7] Dong. China Computer World Network. IT project supervision comparison of three models in 2006.

[8] Li Weihong. Modern computer. Information System Engineering and Project management compared to 2007.

[9] Christopher N S. The Journal of Industrial Economics. Negotiation and renegotiations of finance Contracts under the thread of predation $[\mathrm{J}] 2006$.

[10] Greenwald BC, Joseph E S. American economic Review. Asymmetric information and the new theory of the firm: Financial constraints and risk behavior [J] 2000.

[11]Xiong Jianyu. Modern business education. Management of Information System Engineering, 2009. 